\title{
Subjective Social Status (SSS) as an Important Mediator in the Association between Socioeconomic Status (SES) and Mental Health
}

Fatemeh Mehravar

Tehran University of Medical Sciences

Abbas Rahimi Foroushani

Tehran University of Medical Sciences

Mohammad Ali Vakili

Golestan University of Medical Sciences

Saharnaz Nedjat ( $\square$ nejatsan@tums.ac.ir)

Tehran University of Medical Sciences

\section{Research Article}

Keywords: Socioeconomic Status, Mental health, Subjective Social Status, TUMS Employee's Cohort study

Posted Date: September 22nd, 2021

DOl: https://doi.org/10.21203/rs.3.rs-779522/v1

License: (c) (i) This work is licensed under a Creative Commons Attribution 4.0 International License. Read Full License 


\section{Abstract}

\section{Background:}

Socioeconomic status (SES) has often been considered a major predictor of mental health-related outcomes such as depression, anxiety, and stress. However, little is known about the mediating role of subjective social status (SSS) - an individual perception of relative position in the social hierarchy-in the relationship between SES and health outcomes. This study aimed to determine the mediating role of SSS in the relationship between SES and mental health among the employees of Tehran University of Medical Sciences (TUMS).

\section{Methods:}

The data from the enrolment phase of a cohort study on TUMS employees $(n=4461)$ were used in this cross-sectional study. Household SES was the main independent variable. SES was first entered into the mediation model as a composite index (a combination of wealth index, social class, and education), and then each indicator was entered separately. Stress, anxiety, and depression scores were measured using the DASS-42 Scale as a latent outcome variable for mental health status. SSS was evaluated as a potential mediator variable using the MacArthur scale which was converted to a five-point Likert item. The mediation analysis was carried out using a two-step structural equation modeling (SEM) approach in STATA version 14.0 with maximum likelihood (ML) estimation. Finally, the direct and indirect effects of SES indices on mental health were investigated, considering SSS's mediating role.

\section{Results:}

The data showed that 2706 participants $(60.65 \%)$ were female and the mean age of all participants was $42.21 \pm 8.72$ years. The standardized path coefficient for the direct effect of SES on SSS was -0.50 $(S E=0.013)$, whereas the standardized path coefficient for the direct effect of SSS on mental health was 0.10 (SE=0.018). The standardized indirected effect of the composite SES-index on mental health through the SSS is -0.05 (lower SSS and mental health scores and higher SES scores indicate improvements in the status of these variables). Contribution of SSS in association between composite SES-index and the mental health of TUMS employees is $27.78 \%$ ( $27.27 \%$ in male and $22.23 \%$ in female). In addition, contribution of SSS for the association between the indices of wealth, education, social class and mental health is $41.67 \%, 36.36 \%$, and $28.57 \%$, respectively.

\section{Conclusions:}

The Findings of this study showed that a poorer SSS may influence the pathology of mental health disorders. It seems to be as a mediator in the association between SES and symptoms of depression, anxiety, and stress. Individuals' mental health may thus be improved by intervening in their subjective social status in relation to SES, which is relatively more stable. 


\section{Background}

Mental health is one of the most important aspects of community health. Furthermore, improving mental health indicators leads to increased efficiency and labor productivity in all societies. The World Health Organization (WHO) defines "mental health" as a state of well-being in which an individual recognizes his/her abilities, copes with daily life stressors, works productively and fruitfully, and contributes to his/her community (1). On a global scale, one out of every four people will be affected by a mental or neurological disorder at some point in their lives (2). According to WHO's 2017 estimates, 792 million people worldwide suffer from a mental health disorder across all age groups, with 264 million suffering from depression and 284 million suffering from anxiety disorders. Depression and anxiety are also major causes of disability and contribute significantly to the global burden of disease(3).

The role of socioeconomic status (SES) is critical among environmental factors influencing mental health (4). Numerous studies have examined the relationship between SES and mental health, and the majority of them found that the higher the SES, the better the mental health status, and vice versa (5). Subjective social status (SSS) represents a cognitive average of objective SES indices (including income, education, and occupation status) (6). SSS refers to an individual's perception of his/her social position in relation to other members of society (7). This perceived social status is the result of a procedure known as social comparison. Furthermore, SSS is associated to objective SES indices (8).

In 2000, the concept of SSS was first introduced in health-related research, with the suggestion that SSS can predict psychological and physiological functioning of the body (9). SSS can have an impact on health through psychological pathways (10). For example, feelings of anxiety, stress, and inequality, which are associated with perceptions of low social status, may be associated with health-related physiological responses(11). Furthermore, feelings of security and hope associated with high social status may act as psychological buffers against some stressors through immunological mediators (12).

Numerous studies have found significant association between SSS and various aspects of physical and mental health, even after controlling the effects of objective SES indices(13). The WHO mental health surveys, for example, show significant relationships between SSS and a variety of mental disorders after controlling for objective SES indices (14). A study conducted in Germany indicated that SES associated with depressive symptoms through SSS(15). Also Demakakos et al. in the United States discovered that after controlling objective SES indices, SSS has a significant association with some physical illnesses and depressive symptoms (16).

Despite the fact that many scholars have attempted to explain the socioeconomic gradient in mental health, there is little evidence of causal pathways by which SES affects an individual's mental health status. The purpose of this study was to determine the mediating role of SSS in the association between SES and mental health among TUMS employees.

\section{Methods}




\section{Study area and population}

This study used data from the initial enrolment phase of Tehran University of Medical Sciences (TUMS) employees' cohort study (TEC) in Tehran, Iran. This phase was carried out from the beginning of January 2018 to March 2021. In the cohort study, the sample consisted of the employees of TUMS and other institutes affiliated with this university who were willing to participate in the study $(n=4461)$. The TUMS Research Department formally informed all university-affiliated centers and faculties about the research. At the cohort center, data on the physical and mental health of the participants was collected (17). In the baseline phase of this cohort study examined 766 variables related to the health of the employees. In this present study used the variables such as demographic characteristics, socioeconomic status, educational status, and stress, anxiety, and depression disorders.

\section{Study Variables}

Depression, Anxiety, and Stress Scale (DASS-42): This scales measures depression, anxiety, and stress as proxies of mental health status. It is divided into three subscales: anxiety, depression, and stress, with 14 items in each. The items are graded on a four-point scale: never (score 0 ), rarely (score 1), occasionally (score 2), and always (score 3). The depression subscale assesses dysphoric mood, a lack of confidence, hopelessness, a sense of worthlessness in life, a lack of interest in involvement, a lack of enjoyment, and a lack of energy and strength. The anxiety subscale assesses physiological overarousal, fears, and situational anxieties. Finally, the stress subscale assesses the difficulty in achieving peace, as well as nervous tension, irritability, and restlessness. The tool's validity and reliability have been confirmed in the Iranian population (18), and the scale has frequently been used in studies carried out in $\operatorname{Iran}(19,20)$. A higher score on this scale indicates that the individual suffers from anxiety disorders, depression, and stress to a greater extent.

\section{Objective SES}

Households' socioeconomic status (SES) was made up of components such as education, wealth index, and social class. Education was divided into eight categories (Illiterate, primary, intermediate, diploma, upper diploma, Bachelor of Science, Master of Science and Doctor of Philosophy).

The wealth index was calculated using data about durable assets (dishwasher, microwave, personal computer/laptop, washing machine, LCD/LED TV, DVD Players, home theater systems, access to Internet at home, automobile, total price of automobiles owned by family, number of rooms per person, and floor area per person). After that, the Categorical Principal Components Analysis (CATPCA) was used to calculate the household wealth index (21). It should be noted that higher wealth index scores indicate a higher level of economic well-being.

CATPCA was also used to assess participants' social class by collecting data on things like how frequently they went to music concerts, cinemas, theaters, or restaurants, how many national and international family trips they took, how much money they spent on internet, and how many extracurricular books they read. Higher social class scores indicate a higher level of social status. 


\section{Subjective social status (SSS)}

The SSS mediating variable reflects an individual's perception of his/her (or his/her family's) socioeconomic status in comparison to other members of society $(22,23)$. In this study, the SSS of the participants was assessed using the MacArthur scale which was converted to a five-point Likert scale(9, 24). The participants were asked: Which of the five socioeconomic classes does your family belong to in today's Iranian society? (Upper class: score 1; Upper middle class: score 2; Middle class: score 3; Lower middle class: score 4, and Lower class: score 5). Individuals with higher SSS scores have a worse subjective social status.

\section{Statistical Analyses}

The CATPCA method determined that the first component that explained the greatest proportion of the variance in the composite variable was the best substitute for wealth and social class indices. In PCA technique, a large number of highly correlated variables are converted into a smaller set of uncorrelated variables (25). The variables "mental health, wealth index, and social class" and "education and SSS" were analyzed using "interval" and "ordinal" scales, respectively.

To assess the correlations between the research variables, the Pearson correlation coefficient test was used. The mediation analysis was then carried out using Anderson and Gerbing's two-step SEM (measurement model and structural model) approach (26). Using this method, the direct and indirect effects of SES indices on mental health were investigated while accounting for SSS's mediating role. In SEM, all parameters were estimated using Maximum Likelihood Estimation approach, and indicators of RMSEA $<0.05$, SRMR $<0.08, \mathrm{CFI}>0.9$, and TLI $>0.9$ were used to test goodness of fit of the model (27). All SES indices were first incorporated into the mediation model as the composite SES-index (a combination of wealth index, social class, and education), and then they were inserted into the model separately by using STATA version 14.0 (STATA Corporation, College Station Texas) software.

SSS's mediating role was evaluated by calculating standardized path coefficients for indirect and total effects using the variance accounted for (VAF) formula (28).

Mediation Percentage $($ VAF $)=($ Indirect Effect $/$ Total Effect $) * 100$

VAF values $>80 \%$ indicate full mediation; $20 \%<$ VAF values $<80 \%$ indicate partial mediation, and VAF values $<20 \%$ indicate no mediation (29).

\section{Ethical approval}

for this study was obtained from the Ethics and Research committee of Tehran University of Medical Sciences (TUMS.VCR.REC.1398.829). Before registration, all participants read and sign the informed written consent form. A copy of the signed consent form is given to the participant. The guidelines on research involving the use of human subjects (beneficence, non-maleficence, veracity, confidentiality, and 
voluntarism) were strictly adhered to according to the Helsinki Declaration. Participants did not incur any cost by participating in this study and there was no financial inducement.

\section{Results}

As shown in Table 1, among all 4461 participants, 2706 individuals (60.65\%) were female, and 1755 individuals (39.35\%) were male. The mean age of the male and female participants was 43.23 years (SD $=9.0$; range: $20-73)$ and 41.61 years $(S D=8.40$, range: $19-75)$, respectively. Most of the participants (78.91\%) were married.

As shown in Table 2, SES indices were moderately correlated with each other and with SSS. Among the SES indices, the highest correlation was observed between the wealth index and SSS $(r=0.48, P<0.001)$. Mental health subscales (including depression, anxiety, and stress) were strongly correlated with each other; however, depression had the highest correlation with SSS $(r=0.39, P<0.001)$. These correlations were all moderate. In addition, the wealth index had the highest correlation with mental disorders (especially stress) in comparison with other SES indices $(r=0.51, P<0.001)$.

Table 1

Characteristics of the study population in TUMS Employee's Cohort study

\begin{tabular}{|c|c|c|c|}
\hline \multirow[t]{2}{*}{ variables } & $\begin{array}{l}\text { Total } \\
\mathrm{N}=4461\end{array}$ & $\begin{array}{l}\text { Male } \\
\mathrm{N}=1755\end{array}$ & $\begin{array}{l}\text { Female } \\
N=2706\end{array}$ \\
\hline & Mean (SD) & Mean (SD) & Mean (SD) \\
\hline Age (range: $19-74$ years) & $42.29(8.71)$ & $43.24(9.07)$ & $41.67(8.42)$ \\
\hline Education (range: $1-8$ ) & $5.54(1.44)$ & $5.19(1.56)$ & $5.77(1.30)$ \\
\hline Wealth index (range: -5.08 to 2.84 ) & $-1.01(1.02)$ & $-0.15(1.06)$ & $0.06(0.98)$ \\
\hline Social Class (range: -2.12 to 5.09 ) & $-0.06(1.08)$ & $-0.27(1.05)$ & $0.06(1.07)$ \\
\hline SSS (range: 1-5) & $2.84(0.81)$ & $2.97(0.84)$ & $2.75(0.78)$ \\
\hline Depression (range: 0 to 42 ) & $8.03(8.06)$ & $7.10(7.37)$ & $8.63(8.41)$ \\
\hline Anxiety (range: 0 to 38 ) & $6.03(5.56)$ & $5.48(5.06)$ & $6.38(5.81)$ \\
\hline Stress (range: 0 to 39 ) & $12.63(8.28)$ & $11.58(7.83)$ & $13.31(8.48)$ \\
\hline \multicolumn{4}{|c|}{ SD, standard deviation; SSS, subjective social status. } \\
\hline \multicolumn{4}{|c|}{ High scores of Wealth index and Social index indicate better SES. } \\
\hline \multicolumn{4}{|c|}{ High scores of anxiety, depression, and stress indicate worse status in mental health. } \\
\hline \multicolumn{4}{|c|}{ High score in SSS indicate worse subjective social status. } \\
\hline
\end{tabular}


Table 2

Correlations between indicators of SES, SSS and Mental health outcome (correlation coefficients) $(n=4461)$

\begin{tabular}{|c|c|c|c|c|c|c|}
\hline & Education & Wealth index & Social class & Depression & Anxiety & Stress \\
\hline Wealth index & $0.57 *$ & & & & & \\
\hline Social class & $0.58 *$ & $0.61 *$ & & & & \\
\hline Depression & $-0.31^{\star}$ & $-0.42^{\star}$ & $-0.21^{*}$ & & & \\
\hline Anxiety & $-0.22^{\star}$ & $-0.43^{*}$ & $-0.18^{*}$ & $0.81 *$ & & \\
\hline Stress & $-0.36^{\star}$ & $-0.51^{*}$ & $-0.37 *$ & $0.77 *$ & $0.75^{\star}$ & \\
\hline SSS & $-0.40 *$ & $-0.48^{*}$ & $-0.47 *$ & $0.39 *$ & $0.35^{\star}$ & $0.32^{*}$ \\
\hline$\star P<0.001$ & & & & & & \\
\hline
\end{tabular}

The hypothetical model was analyzed with the variables of composite SES-index, mental health, and the mediating variable of SSS using SEM. Acceptable values were obtained for all goodness-of-fit tests, which are used to assess how well the saturation model fits the hypothetical model (RMSEA $=0.05, \mathrm{CFI}=$ $0.98, \mathrm{TLI}=0.97, \mathrm{SRMR}=0.02$, and $\mathrm{CD}=0.76$ ).

As shown in Fig. 1, in the measurement model, social class $(r=0.73)$ had the greatest effect on the latent variable of SES, and wealth index (0.71) and education (0.65) were ranked second and third in this regard. In other words, social class index explaining 0.73 of socioeconomic status variance. In addition, the variable of stress $(r=0.89)$ had the greatest effect on the latent variable of mental health, and depression (0.87) and anxiety (0.85) were ranked second and third, respectively. Stress explaining 0.89 of mental health variance. Higher SES scores indicate a better socioeconomic status, whereas higher SSS and mental health scores indicate a worsening of these variables' status.

In the SEM structural model, SES had a significant relationship with SSS ( $\beta$ Standardized Directed Effect $=-0.50)$; thus, increasing the SES score by one unit reduces the participants' SSS by 0.50 . In addition, SSS was directly related to mental health $\left(\beta_{\text {Standardized Directed Effect }}=0.10\right)$. In other words, exacerbation of the SES of the university employee worsens their SSS, which in return deteriorates their mental health status.

The direct, indirect, and total effects were determined to assess the potential mediating role of SSS in the relationship between SES indices had mental health (Table 3). Based on the results, composite SES-index and SES indices had indirect effects on mental health through SSS. The standardized indirect effect of composite SES-index on mental health through SSS was - 0.05. Therefore, Contribution of SSS in association between composite SES-index and mental health of TUMS employees is $27.78 \%$ (As the calculation method was given in the statistical analyses section). SES indices had also significant 
indirect effects on the mental health through SSS. Contribution of SSS for the association between the indices of wealth, education, social class and mental health is $41.67 \%, 36.36 \%$, and $28.57 \%$, respectively.

Figure 2 shows the indirect effect of SES on the mental health through SSS for both women ( $\beta_{\text {Standardized }}$ Indirected Effect $=-0.06$ ) and men ( $\beta$ Standardized Indirected Effect $=-0.03$ ). For example, one unit increase in the SES score of the female employees reduces their mental health score by 0.06 through SSS. Finally, Contribution of SSS in association between the composite SES-index and the mental health of TUMS employees is $27.27 \%$ in male and $22.23 \%$ in female.

Table 3

Mediation analysis of the association between SES and mental health through SSS in TEC study ( $\mathrm{n}=$ 4461).

\begin{tabular}{|lllll|}
\hline $\begin{array}{l}\text { Paths } \\
\text { (mediated by SSS) }\end{array}$ & $\begin{array}{l}\text { Direct } \\
\text { Effect (SE) }\end{array}$ & $\begin{array}{l}\text { Indirect Effect } \\
\text { through the } \\
\text { SSS (SE) }\end{array}$ & $\begin{array}{l}\text { Total } \\
\text { Effect(SE) }\end{array}$ & $\begin{array}{l}\text { percentage of variance } \\
\text { accounted for(VAF) } \\
\text { by SSS }\end{array}$ \\
\hline $\begin{array}{l}\text { SES } \rightarrow \text { Mental } \\
\text { Health }\end{array}$ & $-0.14(0.02)$ & $-0.05(0.01)$ & $\begin{array}{l}-0.18 \\
(0.01)\end{array}$ & 27.78 \\
\hline $\begin{array}{l}\text { Education } \rightarrow \text { Mental } \\
\text { Health }\end{array}$ & $-0.07(0.01)$ & $-0.04(0.01)$ & $\begin{array}{l}-0.11 \\
(0.01)\end{array}$ & 36.36 \\
$\begin{array}{l}\text { Wealth Index } \rightarrow \\
\text { Mental Health }\end{array}$ & $-0.07(0.03)$ & $-0.05(0.01)$ & $\begin{array}{l}-0.12 \\
(0.03)\end{array}$ & 41.67 \\
$\begin{array}{l}\text { Social Class } \rightarrow \\
\text { Mental Health }\end{array}$ & $-0.09(0.01)$ & $-0.04(0.01)$ & $\begin{array}{l}-0.14 \\
(0.01)\end{array}$ & 28.57 \\
\hline
\end{tabular}

- Direct effect = the pathway from the SES to the Mental Health while controlling for the SSS.

- Indirect or mediated effect = the pathway from the SES to the Mental Health through the SSS.

- Total effect $=$ direct effect + indirect effect.

- VAF= (Indirect Effect/ Total Effect) $₫ 100$

- VAF $<0.2$, no mediation; $0.2 \leq V A F \leq 0.8$, partial mediation; $V A F>0.8$, full mediation.

- All of P-value is less than 0.001

\section{Discussion}

The data from the enrolment phase of a cohort study conducted on TUMS employees was used in this study to determine the role of SSS as a mediator in the relationship between SES and the mental health. According to the results of the present study, subjective social status partially mediated effects of SES on the mental health in women and men TUMS employees. In other words SSS contribute to $27.78 \%$ of the explanation of SES in the mental health. 
Only few studies have used SEM to investigate the effects of the aforementioned variables on mental health simultaneously. Hoebel et al. used sequential logistic regression models in 2017 to investigate the role of SSS as a mediator in the relationship between SES and depressive symptoms in a sample of approximately 5000 German adults. The results of the mediation analysis showed an indirect relationship between SES and depressive symptoms through SSS, with SSS accounting for $34.78 \%$ of the effect of SES on depressive symptoms (46.15\% in men and $27.27 \%$ in women)(15). In line with the present results, Hoebel et al. also observed that SSS mediated a higher percentage of the relationship in men than in women. Demakakos et al. (2008) examined the relationship between SES and health using data from the English Longitudinal Study of Aging in the United States. Their study population consisted of 3368 men and 4065 women aged 52 years or older. They discovered that in both men and women, SSS mediates the relationships between objective SES indices and depression and some chronic physical illnesses. SSS also mediated the relationships between education and occupational class and depression; however, it had no role in mediating the relationship between wealth and health outcomes. Since multivariate regression analysis was used to mediate, indirect effects and the contribution of the SSS variable were not reported(16).

In our study, SSS mediated more than $40 \%$ of the effect of the wealth index on the mental health. In a study on Iranian participants, Beigi et al. found that SSS has the highest correlation with wealth index among all objective SES indices(24). In a population-based study conducted in rural Uganda, people who perceived themselves to be less wealthy were more likely to develop depression than those who perceived themselves to be wealthier (the effects of other objective SES indices were controlled for) (30). Therefore, in similar studies, scholars can use the single-item tool of SSS rather than the relatively sophisticated tool of ASSET.

In present study, SSS mediated $36.36 \%$ and $28.57 \%$ of the effects of education and social class on the mental health, respectively. Most studies have highlighted the leading role of economic status in the incidence of mental health disorders(31, 32); however, Hoebel et al. observed that education has the strongest relationship with depressive symptoms among all objective SES indices(15). In the present study, the most prominent mediating role of SSS was observed in the relationship between wealth index and mental health (41.67\%), with education ranking second. In the case of occupational class, the results of studies are highly contradictory $(33,34)$, which is most likely due to differences in occupational classification in different countries.

In our study, Higher SES scores were found to reduce the prevalence of mental disorders (including depression, anxiety, and stress) in both men and women. In a great study of approximately one million people living in 55 regions of Sweden, factors such as low social support, social humiliation, low employment status, and economic problems were found to be independently associated with mental health symptoms; however, education had no significant effect on the participants' mental health status (35). According to Wang et al., a low SES contributes to the development of major depressive disorder in the general Canadian population; however, this association depends on factors of gender and employment status. For example, working men from low-income families, as well as unemployed men 
and women with poor economic status, were more likely than others to suffer from major depression (36).

Our results indicate that social class index explaining 0.73 of socioeconomic status variance which has been more than education and wealth index. Therefore, it can be suggested that in future studies, the social class index be used as one of the important indicators determining the SES. Another strength of the study was the large size of the study sample. Furthermore, the SEM model has many advantages over regression and classical models in that it estimates the relationships between several manifest and latent variables while correcting for measurement error. Besides, standardized coefficients allowed the researchers to compare various types of variables with one another.

\section{Study Limitations}

Given the lack of a standard occupational classification system in Iran and the fact that there are people ranging from very rich to very poor in a single occupation class in available systems, the role of SSS in mediating the relationship between occupation and mental health was not evaluated. Due to the large number of participants, self-reported tools were used to assess the mental health of the TUMS employees, which was another limitation of the present study.

Because of the cross-sectional nature of the study, the researchers were unable to determine causal associations and Causal directions between variables, and they were unable to examine causal mediation in the mediation analysis process. In This study only the consistency of the hypothetical mediation model with the data used was confirmed by the results. To overcome this limitation, prospective data must be used in determining the causality of the hypotheses. Other phases of the TUMS employees' cohort study will be completed in the future; thus, using the prospective data, the researchers will be able to reassess the analyzed relationships and compare the obtained results with the current findings, allowing them to draw more valid conclusions.

Because the study population consisted of all TUMS employees, the results must be carefully generalized to the general population. However, the fact that the selected employees came from a variety of age groups and occupational backgrounds (e.g., administrative, service, educational, and medical groups) contributed to the diversity of their socioeconomic status.

\section{Conclusion}

Subjective social status, which refers to a person's perception of his/her social position in relation to other members of society, accounts for a considerable contribution $(27.78 \%)$ of the effect of the composite SES-index on common mental health disorders (e.g., depression, anxiety, and stress). SSS's mediating role in this relationship is most likely related to the formation of capabilities and individuals' social and economic status. Therefore, it is suggested that in future studies, the effect of SES on various aspects of 
health be investigated through other causal pathways and the contribution of other effective factors should be determined.

\section{Abbreviations}

TUMS

Tehran University of Medical Sciences

SES

Socioeconomic Status

SSS

Subjective Socioeconomic Status

DASS

Depression. Anxiety and Stress Scale

STATA

software for data science and statistical analysis

SEM

structural equation modeling

$\mathrm{ML}$

maximum likelihood

TEC study

Tehran University of Medical Sciences employees`cohort

CATPCA

Categorical Principal Components Analysis

RMSEA

Root Mean Square Error of Approximation

SRMR

Standardized Root Mean Square Residuals

CFI

comparative fit index

TLI

Tucker-Lewis index

CD

coefficient of determination

VAF

variance accounted for

SD

standard deviation.

\section{Declarations}




\section{Ethics approval and consent to participate}

Ethical approval for this study was obtained from the Ethics and Research committee of Tehran University of Medical Sciences (TUMS.VCR.REC.1398.829). Before registration, all participants read and sign the informed written consent form. A copy of the signed consent form is given to the participant. The guidelines on research involving the use of human subjects (beneficence, non-maleficence, veracity, confidentiality, and voluntarism) were strictly adhered to according to the Helsinki Declaration. Participants did not incur any cost by participating in this study and there was no financial inducement.

\section{Consent for publication}

Not applicable.

\section{Availability of data and material}

The datasets of participants used and analyzed during the current study were acquired from the enrolment phase of Tehran University of Medical Sciences employees`cohort (TEC) study. However, the datasets collected during the current study are available from the corresponding author on reasonable request.

\section{Competing interests}

The authors declare that they have no competing interests.

\section{Funding}

This project was financially supported by the deputy of research and technology of the ministry of health and the medical education of the Islamic Republic of Iran. The funding body was not involved in the design of the study or collection, analysis, and interpretation of data or writing of this manuscript.

\section{Authors' contributions}

F.M drafted the manuscript, contributed to the conception, and performed the analytic calculations and interpretation of data. A.RF designed the statistical model, the computational framework. MA.V analysed the data, the computational framework. S.N conceived of the presented idea, collection data management, designed the study and critically revising analysis and manuscript. All authors read and approved the final manuscript.

\section{Acknowledgements}


The authors are grateful to patients, who participated in the study, for their time to participate in the study. We are also grateful to the Vice Chancellor for Research Affairs at the Tehran University of Medical Science for their support.

\section{References}

1. Herrman H, Saxena S, Moodie R. Organization WH Promoting mental health: concepts, emerging evidence, practice: a report of the World Health Organization, Department of Mental Health and Substance Abuse in collaboration with the Victorian Health Promotion Foundation and the University of Melbourne.

2. Guilbert J. The World Health Report 2001-Mental Health: New Understanding, New Hope. Education for Health. 2002;15(2):263-4.

3. Rudd KE, Johnson SC, Agesa KM, Shackelford KA, Tsoi D, Kievlan DR, et al. Global, regional, and national sepsis incidence and mortality, 1990-2017: analysis for the Global Burden of Disease Study. The Lancet. 2020;395(10219):200-11.

4. Adler NE, Ostrove JM. Socioeconomic status and health: what we know and what we don't. Annals of the New York academy of Sciences. 1999;896(1):3-15.

5. Hanson MD, Chen E. Socioeconomic status and health behaviors in adolescence: a review of the literature. Journal of behavioral medicine. 2007;30(3):263.

6. Wangberg SC, Andreassen HK, Prokosch H-U, Santana SMV, Sørensen T, Chronaki CE. Relations between Internet use, socio-economic status (SES), social support and subjective health. Health promotion international. 2008;23(1):70-7.

7. Adler NE, Boyce T, Chesney MA, Cohen S, Folkman S, Kahn RL, et al. Socioeconomic status and health: the challenge of the gradient. American psychologist. 1994;49(1):15.

8. Rarick JR, Dolan CT, Han WJ, Wen J. Relations between socioeconomic status, subjective social status, and health in Shanghai, China. Social Science Quarterly. 2018;99(1):390-405.

9. Adler NE, Epel ES, Castellazzo G, Ickovics JR. Relationship of subjective and objective social status with psychological and physiological functioning: Preliminary data in healthy, White women. Health psychology. 2000;19(6):586.

10. Destin M, Richman S, Varner F, Mandara J. "Feeling” hierarchy: The pathway from subjective social status to achievement. Journal of adolescence. 2012;35(6):1571-9.

11. Operario D, Adler NE, Williams DR. Subjective social status: Reliability and predictive utility for global health. Psychology \& health. 2004;19(2):237-46.

12. Steptoe $A$, Marmot $M$. The role of psychobiological pathways in socio-economic inequalities in cardiovascular disease risk. European heart journal. 2002;23(1):13-25.

13. Sasaki Y, Shobugawa Y, Nozaki I, Takagi D, Nagamine Y, Funato M, et al. Association between depressive symptoms and objective/subjective socioeconomic status among older adults of two regions in Myanmar. PloS one. 2021;16(1):e0245489. 
14. Scott KM, Al-Hamzawi AO, Andrade LH, Borges G, Caldas-de-Almeida JM, Fiestas F, et al. Associations between subjective social status and DSM-IV mental disorders: results from the World Mental Health surveys. JAMA psychiatry. 2014;71(12):1400-8.

15. Hoebel J, Maske UE, Zeeb H, Lampert T. Social inequalities and depressive symptoms in adults: the role of objective and subjective socioeconomic status. PloS one. 2017;12(1):e0169764.

16. Demakakos P, Nazroo J, Breeze E, Marmot M. Socioeconomic status and health: the role of subjective social status. Social science \& medicine. 2008;67(2):330-40.

17. Nedjat S, Mehrdad R, Yunesian M, Pouragha H, Biagi V, Monazzam-Esmaeelpour MR. Prospective cohort study on the social determinants of health: Tehran University of Medical Sciences employeescohort (TEC) study protocol. BMC public health. 2020;20(1):1-7.

18. Al-Gelban KS, Al-Amri HS, Mostafa OA. Prevalence of depression, anxiety and stress as measured by the depression, anxiety, and stress scale (DASS-42) among secondary school girls in Abha, Saudi Arabia. Sultan Qaboos University Medical Journal. 2009;9(2):140.

19. Afzali A, Delavar A, Borjali A, MIRZAMANI M. Psychometric properties of DASS-42 as assessed in a sample of Kermanshah High School students. 2007.

20. Hosseinrezaei $H$, Pilevarzadeh M, Amiri M, Rafiei H, Taghati S, Naderi M, et al. Psychological symptoms in family members of brain death patients in intensive care unit in Kerman, Iran. Global journal of health science. 2014;6(2):203.

21. Sartipi M, Nedjat S, Mansournia MA, Baigi V, Fotouhi A. Assets as a socioeconomic status index: categorical principal components analysis vs. latent class analysis. Archives of Iranian medicine. 2016;19(11):0-.

22. Howe LD, Galobardes B, Matijasevich A, Gordon D, Johnston D, Onwujekwe O, et al. Measuring socioeconomic position for epidemiological studies in low-and middle-income countries: a methods of measurement in epidemiology paper. International journal of epidemiology. 2012;41(3):871-86.

23. Quon EC, McGrath JJ. Subjective socioeconomic status and adolescent health: a meta-analysis. Health Psychology. 2014;33(5):433.

24. Baigi V, Nedjat S, Fotouhi A, Janani L, Mohammad K. Subjective social status in association with various health and socioeconomic indicators in Tehran. Journal of Public Health. 2016;24(6):497503.

25. Vyas S, Kumaranayake L. Constructing socio-economic status indices: how to use principal components analysis. Health policy and planning. 2006;21(6):459-68.

26. Anderson JC, Gerbing DW. The effect of sampling error on convergence, improper solutions, and goodness-of-fit indices for maximum likelihood confirmatory factor analysis. Psychometrika. 1984;49(2):155-73.

27. Hooper D, Coughlan J, Mullen M. Structural Equation Modelling: Guidelines for Determining Model Fit. Articles; 2008: 2.

28. Mahmud N, Hilmi MF, Mustapha YAA, Abu Karim R. Total quality management and SME performance: the mediating of innovation in Malaysia. Asia-Pacific Management Accounting Journal 
(APMAJ). 2019;14(1):201-17.

29. Hair JF, Ringle CM, Sarstedt M. PLS-SEM: Indeed a silver bullet. Journal of Marketing theory and Practice. 2011;19(2):139-52.

30. Smith ML, Kakuhikire B, Baguma C, Rasmussen JD, Perkins JM, Cooper-Vince C, et al. Relative wealth, subjective social status, and their associations with depression: Cross-sectional, populationbased study in rural Uganda. SSM-population health. 2019;8:100448.

31. Hounkpatin HO, Wood AM, Brown GD, Dunn G. Why does income relate to depressive symptoms? Testing the income rank hypothesis longitudinally. Social Indicators Research. 2015;124(2):637-55.

32. Schlax J, Jünger C, Beutel ME, Münzel T, Pfeiffer N, Wild P, et al. Income and education predict elevated depressive symptoms in the general population: results from the Gutenberg health study. BMC public health. 2019;19(1):1-10.

33. Evans-Lacko S, Aguilar-Gaxiola S, Al-Hamzawi A, Alonso J, Benjet C, Bruffaerts R, et al. Socioeconomic variations in the mental health treatment gap for people with anxiety, mood, and substance use disorders: results from the WHO World Mental Health (WMH) surveys. Psychological medicine. 2018;48(9):1560-71.

34. Von dem Knesebeck O, Lüschen G, Cockerham WC, Siegrist J. Socioeconomic status and health among the aged in the United States and Germany: a comparative cross-sectional study. Social science \& medicine. 2003;57(9):1643-52.

35. Gedin F, Alexanderson K, Zethraeus N, Karampampa K. Productivity losses among people with back pain and among population-based references: a register-based study in Sweden. BMJ open. 2020;10(8):e036638.

36. Wang JL, Schmitz N, Dewa CS. Socioeconomic status and the risk of major depression: the Canadian National Population Health Survey. Journal of Epidemiology \& Community Health. 2010;64(5):447-52.

\section{Figures}

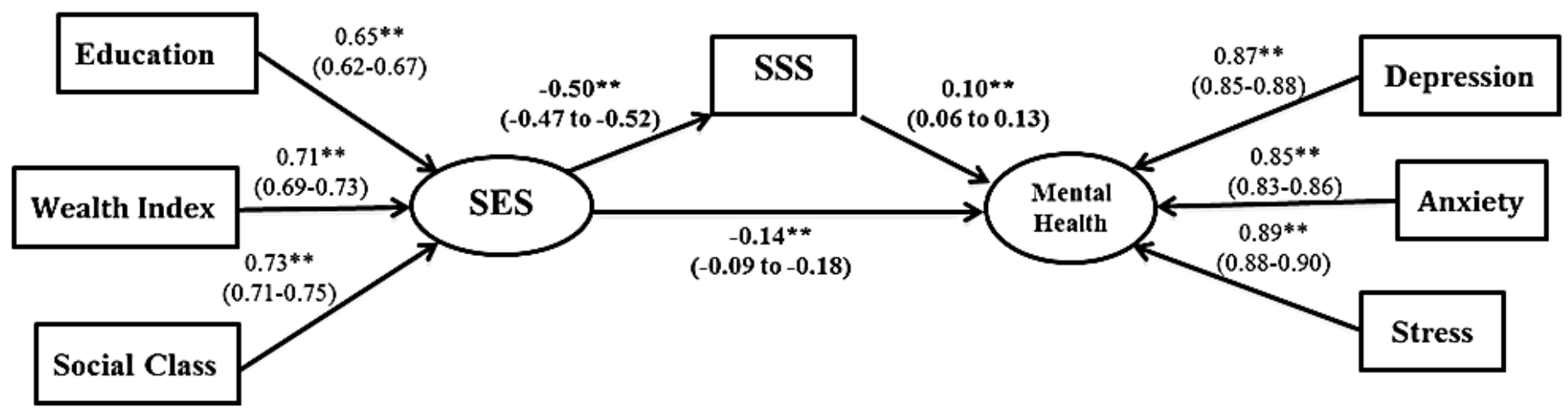

Figure 1 
measurement and structural models in structural equation modelling of the association between socioeconomic status (SES) and mental health through SSS in TUMS Employee's Cohort study $(n=4461)$. Standardized directed coefficients are out of parentheses and 95\% $\mathrm{Cl}$ in parentheses. ${ }^{* *} \mathrm{P}<0.001$.
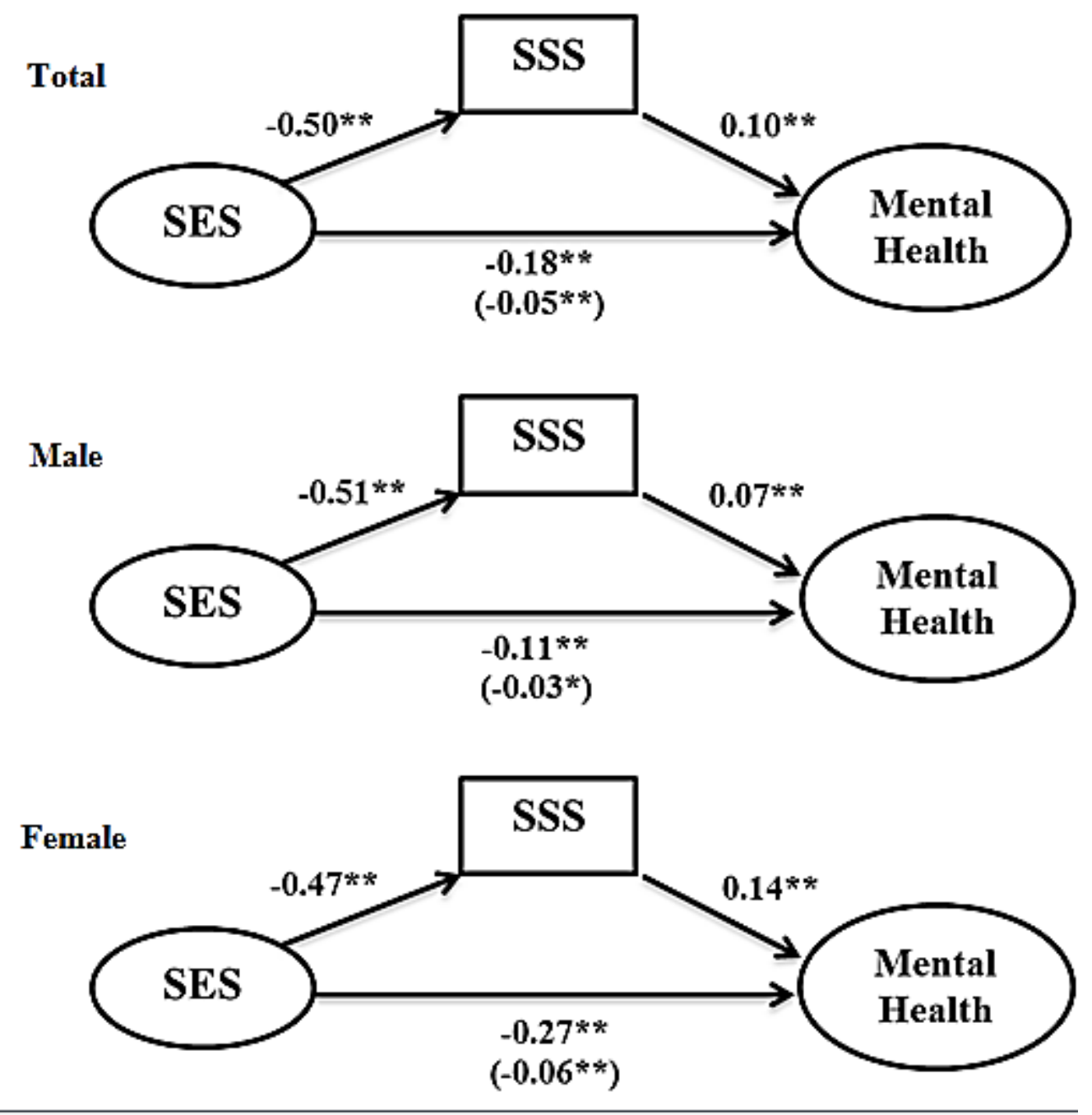

Figure 2

Mediation analysis model of the association between socio-economic status (SES) and mental health through SSS in TUMS Employee's Cohort study by gender ( $n=4461 ; n m e n=1755$; nwomen $=2706$ ). Standardized coefficients for Total effect presented and Standardized coefficients for indirect effects presented in parentheses. SSS and mental health was reverse-scored so that higher values reflected worse Status. ** $P<0.001,{ }^{*} P<0.05$ 